\title{
Contra «la tiranía del mostrador». La campaña de la prensa y los trabajadores por el descanso dominical en Tucumán del entresiglo/
}

\author{
Against the «counter tyranny». \\ The Press' and Workers' Campaign for Sunday Rest \\ in Tucumán at the Turn of the Century
}

Vanesa E. Teitelbaum

Instituto Superior de Estudios Sociales CONICET-UNT). Argentina

Este estudio pretende contribuir al análisis de la conformación de la cuestión social y obrera en el Tucumán del entresiglo XIX a XX y, en particular, al papel que desempeñaron en estos procesos dos actores claves y muy poco explorados: las sociedades de trabajadores y la prensa. Con ese propósito, el artículo presta especial atención a la campaña por el descanso dominical que articuló las propuestas y reclamaciones de El Orden, uno de los principales diarios de la época, con las demandas encabezadas por las sociedades mutuales y gremiales que reclamaban este derecho.

Palabras clave: Cuestión social; Cuestión obrera; Prensa; Asociaciones de trabajadores; Descanso dominical

This study seeks to contribute to the analysis of the building process of the social and working issue in Tucuman at the turn of the century. Focus is particularly placed on the role that two rarely studied key actors played in the processes: workers' associations and the press. It is with this purpose that the article pays special attention to the campaign for Sunday rest which articulated proposals and complaints in El Orden -one of the main newspapers of the time-with demands made by benefit societies and unions claiming such right.

KeYwords: Social Issue; Working Issue; Press; Worker’Associations; Sunday Rest. 
Este trabajo busca explorar el papel que desempeñaron las sociedades de trabajadores, y en especial la prensa, en los procesos de construcción de la cuestión social y obrera en Tucumán del entresiglo. ${ }^{1}$ Más particularmente, en las páginas que siguen intentaré avanzar en el lugar clave que considero alcanzó el diario El Orden en la construcción y difusión de una agenda de temas encaminada a mejorar múltiples facetas de la cuestión social en la provincia. Dentro de un extenso abanico de reclamaciones y denuncias sobre la situación que afectaba a los trabajadores, se destacó la demanda por el descanso dominical. En efecto, desde los primeros años del novecientos y hasta su sanción como ley en 1907, puso en difusión campañas a favor de esta medida, apoyando al mismo tiempo las iniciativas de las sociedades de peluqueros y dependientes de comercio que luchaban por conseguir este derecho.

El recorte temporal elegido se inicia aproximadamente en 1896, cuando se abolieron las leyes de conchabo, sistema laboral coactivo establecido para todos los individuos de ambos sexos que carecían de renta propia o de ocupación lícita capaz de garantizarles su subsistencia, ${ }^{2}$ y finaliza en 1907, con la ley de descanso dominical. Durante este periodo, argumento, tuvieron lugar algunas transformaciones significativas en las percepciones acerca del papel del Estado ante la problemática social y especialmente laboral. Sin desplazar del todo las premisas paternalistas, moralizadoras y liberales, ${ }^{3}$ algunas voces provenientes del campo intelectual, político, profesional y gremial, comenzaron a clamar por un papel más activo de las autoridades en el terreno de lo social y laboral. ${ }^{4}$ En ese contexto, cobraron impulso las discusiones y propuestas que abogaban por

1 Una primera versión de este trabajo se discutió en el 53. ${ }^{\circ}$ Congreso Internacional de Americanistas, celebrado en México del 19 al 24 de julio de 2009.

2 El análisis de las leyes de conchabo se encuentra especialmente en Campi, 1993 y Bravo, 2000, pp. 31-61. Más adelante se expondrán en este trabajo algunos rasgos que caracterizaron la definición y el funcionamiento de este sistema laboral coactivo.

3 Juan Suriano se refiere al predominio de la visión liberal que implicaba una política social sin la participación del Estado o que admitía solamente su intervención a través del control y reglamentación. A su vez, señala cómo el mundo del trabajo se estructuraba mediante un sistema de obligaciones y tutelas morales dirigido a los trabajadores, a quienes se consideraba como menores de edad, individuos irresponsables e incapaces de resolver sus problemas básicos de subsistencia, a través del patronato filantrópico (Suriano, 2001, pp. 123-147 y pp. 127-128). Las percepciones sobre los trabajadores en Tucumán en Bravo, 2004, pp. 31-61.

4 Daniel Campi señala la inflexión producida en el discurso social en Tucumán en ese periodo, cuando se vislumbraron agudas críticas sobre las condiciones de vida de los trabajadores, así como propuestas que otorgaban al Estado un papel muy diferente al de mero regimentador de los trabajadores que había desempeñado hasta entonces. En tal sentido, analiza las miradas de intelectuales, como 
elevar el nivel de vida de los trabajadores, haciendo especial hincapié en los temas de vivienda, condiciones laborales, situación de las mujeres trabajadoras, papel de las madres y el problema del trabajo infantil. Estos tópicos englobados en lo que genéricamente se denominó como «cuestión social» generaron proyectos, discursos y alternativas que devenían de diferentes ámbitos profesionales, así como de diversas coordenadas ideológicas y políticas, pero que tenían en común la problemática de los trabajadores y sus condiciones de vida. ${ }^{5}$

Como ya ha sido señalado en la literatura sobre el tema, en Argentina, entre finales del siglo XIX y especialmente al despuntar la nueva centuria, el aumento de la protesta social y especialmente obrera, actuó como el principal detonador de estos debates que involucraron a un conjunto heterogéneo de voces, ${ }^{6}$ como las de médicos higienistas, funcionarios del Estado, intelectuales, líderes religiosos y dirigentes políticos. ${ }^{7}$ Menos estudiado pero no menor fue el papel desempeñado en la construcción de la cuestión social por las sociedades mutuales que — siguiendo a Juan Suriano- reclamaron medidas sociales básicas como la cobertura médica y la ayuda solidaria. Por su parte, la prensa adquirió un lugar primordial en la difusión y puesta en marcha de la cuestión social al asumir, como sostiene este autor, la responsabilidad de dar a conocer y poner en locución una amplia gama de problemas sociales que abarcaban desde las condiciones de hacinamiento de la vivienda popular hasta el estado sanitario de la población. ${ }^{8}$ A pesar de la importancia de la prensa en la enunciación y difusión de la cuestión social, prácticamente no existen trabajos históricos que aborden este tema; las pocas excepciones provienen de los

Julio P. Ávila, que se pronunciaron, no sin contradicciones, por un papel más activo del Estado en el terreno laboral. Campi, 2005, pp. 123-146 y Campi, 2004. Sobre el papel de los médicos higienistas en la conformación de las primeras medidas de política social en la provincia de Tucumán en los años del tránsito entre los dos siglos, Teitelbaum, 2009, pp. 41-68.

5 Aportes teóricos para el estudio de la cuestión social en Rosanvallón, 1995 y Castel, 1997. Para un tratamiento del tema en Argentina se pueden consultar, en especial: Zimmermann, 1995, Falcón, 1999-2000, Lobato, 1999-2000, Masés, 1999-2000, Rafart, 1999-2000 y Suriano 2004a.

6 En especial, sigo a Suriano, que otorga un lugar destacado al conflicto social en la emergencia y desarrollo de la cuestión social, la cual — según propone- surge en la década del 70 pero adquiriere plena visibilidad en la agenda pública hacia comienzos del siglo XX (Suriano, 2004a, pp. 1-29).

7 En esa dirección, resultaron esenciales los artículos de González Leandri y Armus, que prestaron especial atención a la mirada médica sobre la cuestión social en Buenos Aires, y el de Lobato centrado en la legislación femenina y el trabajo infantil (González Leandri, 2004, pp. 217-243, Armus, 2004, pp. 191-216 y Lobato, 2004, pp. 245-275).

8 Suriano, 2001, pp. 123-147 y Suriano, 2004b, pp. 33-58. 
aportes que se abocaron especialmente a las ciudades de Buenos Aires y Rosario, tal como señala Suriano. ${ }^{9}$

En esa perspectiva de análisis, este estudio pretende contribuir al análisis de la conformación de la cuestión social y obrera en Tucumán y, en particular, al papel que desempeñaron en estos procesos dos actores claves y muy poco explorados: las sociedades de trabajadores y la prensa. Con ese propósito, y tras una breve caracterización de la industrialización, urbanización y normativa laboral en la época, trataré de avanzar en el examen del diario El Orden, que reclamó respuestas por parte del Estado para mejorar las condiciones de vida y de trabajo y, paralelamente, alentó a los trabajadores a constituir asociaciones, percibidas como una vía eficaz para fortalecer sus demandas. En esa tónica, el trabajo incluye también una reconstrucción somera sobre el movimiento asociativo de los trabajadores que adquirió mayor impulso entre mediados de la década de 1890 y especialmente al despuntar la nueva centuria. Posteriormente, el artículo se enfoca al examen de un aspecto puntual: la lucha por el descanso dominical, campaña que articuló las propuestas y reclamos de El Orden con las demandas encabezadas por las sociedades mutuales y gremiales que reclamaban este derecho.

\section{La ciudad y el trabajo en Tucumán del entresiglo}

En Tucumán, durante la segunda mitad del siglo XIX y, especialmente hacia 1880 , en el periodo de «auge y consolidación» de la industria azucarera, aumentó el requerimiento de mano de obra para las distintas tareas de la zafra y la recolección de la caña. Al calor de este desarrollo agroindustrial que desplazó actividades de corte artesanal, ganadero y agrícola hacia la producción mayoritaria de un cultivo - la caña de azúcar - se constituyeron nuevos poblados que transformaron el paisaje agrario e impactaron en el medio urbano. ${ }^{10}$ Esta industrialización basada en la especialización azucarera promovió un aumento considerable de la población y alentó la urbanización y la modernización. En efecto, la población de la

9 Suriano, 2004b, pp. 43-44. De los pocos trabajos que abordan esta temática, me apoyo especialmente en los de Prieto, 2000, pp. 105-119 y Prieto, 2004, pp. 63-87.

10 Retomo y amplio la descripción realizada en Teitelbaum, 2009. Sobre la industrialización azucarera en Tucumán véase, en especial, Guy, 1981; Girbal De Blacha, 1991; Bravo, 2008; Campi, 2002 y Sánchez Román, 2005. 
provincia se incrementó de 108.953 habitantes, registrados en el Primer Censo Nacional de 1869, a 215.742 computados en el Segundo Censo Nacional, en 1895. Durante ese periodo se implementaron reformas y mejoras edilicias y se introdujeron algunas innovaciones claves del «progreso» y la «modernidad». Estas transformaciones y avances tecnológicos se manifestaron sobre todo en la capital y centro administrativo y comercial de la provincia, la ciudad de San Miguel de Tucumán, en donde surgieron nuevas casas de depósitos y emisiones de dinero (como los bancos de Tucumán, de San Juan y de la provincia de Tucumán), se establecieron nuevos medios de comunicación, como el telégrafo en 1873, la empresa de teléfonos en 1880 y el ferrocarril en 1876, que modificó completamente la fisonomía de la urbe y dio paso a la creación de nuevos sectores urbanos alrededor de las estaciones ferroviarias. Además, en la década de 1880 tuvo lugar la construcción de bulevares, la apertura de todas las calles del radio urbano y la inauguración del alumbrado eléctrico. Más tarde, en 1898, el gobierno de Lucas Córdoba implementó el sistema de agua corriente en la ciudad. En el municipio capital se registró a su vez el principal aumento de la población que se incrementó en un $96 \%$ entre los dos censos nacionales: de 17.438 habitantes registrados en 1869 pasó a 34.306 en $1895 .{ }^{11}$

A pesar de estas mejoras, las condiciones de vida de la población revelaban serias deficiencias, especialmente graves en las clases populares que habitaban mayoritariamente en viviendas precarias, casi siempre ranchos, localizadas en espacios signados por la ausencia de servicios públicos e infraestructura sanitaria. ${ }^{12}$ En ese contexto, es factible comprender que, en consonancia con la situación observada en otras provincias argentinas, especialmente graves en algunas regiones como el Norte, los trabajadores en Tucumán se enfrentaran, en su mayoría, a problemas derivados de la falta de salubridad, la carencia de servicios y el hacinamiento habitacional. Asimismo, y tal como ya ha sido señalado por la literatura sobre el tema en Argentina, la excesiva duración de la jornada laboral, los accidentes, la inestabilidad y la debilidad en el salario constituyeron los rasgos más

11 Breves Contribuciones del Instituto de Estudios Geográficos, 1988; Curia de Villeco y Bolognini, 1992; Saltor, 1993, pp. 33-61 y Fernández, 2004.

12 Fernández, 2005 y Teitelbaum, 2009. En tal sentido, resulta importante anotar que los procesos de planificación y modernización se limitaron al sector central de la ciudad, en donde la edificación era completa y los servicios de luz eléctrica y agua corriente se hallaban extendidos. Por el contrario, en el espacio urbano restante de ella proliferaban los terrenos baldíos y carentes de servicios (Bravo y Teitelbaum, 2009, p.68). 
típicos que afectaron al mundo del trabajo tucumano en la época, ${ }^{13}$ caracterizado por la heterogeneidad y segmentación. ${ }^{14}$

Uno de los rasgos centrales que definieron el universo laboral en Tucumán, en especial de los peones y jornaleros, fue el establecimiento e impulso a una serie de normativas y leyes de compulsión al trabajo expresadas en las disposiciones contra la vagancia. En ese marco, se situó el Reglamento General de Policía de 1877, que en su definición como vagos incluía a todos los individuos de ambos sexos que carecían de oficio, renta, sueldo u ocupación, a los que teniendo un oficio no lo ejercían habitualmente y a aquellos que disponiendo de una pequeña renta frecuentaban casas de juego y tabernas. De acuerdo a lo estipulado por este Reglamento, quienes resultaban acreedores a la clasificación como vagos debían ocuparse al servicio de algún propietario o industrial mediante un acto legalizado a través de la papeleta de conchabo, en la cual tenía que anotarse la ocupación del trabajador y el patrón asignado. Tal como sostiene María Celia Bravo, dentro de las características que imprimía esta normativa a las condiciones de trabajo se encontraban, por ejemplo, las referidas a la duración de la jornada laboral, la cual se prolongaba de sol a sol, con descansos de dos horas a medio día en los meses de verano y una hora los restantes meses del año, y la facultad del patrón de aplicar castigos «moderados» para corregir las conductas indisciplinadas de los jornaleros. ${ }^{15}$

Siguiendo también a Bravo, interesa señalar que en 1888 «el ordenamiento laboral se desvinculó del reglamento de policía con la sanción de la primera ley de trabajo en la provincia, denominada «De Conchabos», que

13 Un panorama general de la situación que enfrentaban los trabajadores argentinos, en Suriano, 2007, pp. 67-95. Para Tucumán, Fernández, 2005 y Bravo y Teitelbaum, 2009.

14 En Tucumán, el Distrito Capital albergaba un mundo del trabajo caracterizado por su segmentación y heterogeneidad, que iba desde los trabajadores por cuenta propia a los dependientes en los distintos establecimientos que existían en la ciudad. Dentro de los oficios existentes, se encontraban los sastres, los zapateros, los talabarteros y los impresores, pero los más numerosos eran aquellos vinculados con la construcción —albañiles, carpinteros y cortadores de material—; los referidos a la alimentación — panaderos, cocineros, licoreros y queseros-y los concernientes a la metalurgia, como herreros, fundidores y hojalateros. El proceso de desarrollo económico, modernización y urbanización propició, además, el aumento de empleados de comercio y de ocupaciones relacionadas con el transporte, como cocheros, carroceros y ferroviarios. Por otra parte, las fábricas de azúcar y de alcohol instaladas en la zona rural del departamento Capital brindaban trabajo a un contingente numeroso de peones y obreros, tanto para el laboreo en la fábrica, como para el cultivo, cosecha y acarreamiento de materia prima. En el caso del trabajo femenino, éste involucraba a las fábricas, labores a domicilio mujeres costureras, cigarreras, alpargateras, etc.- y ocupaciones relacionadas con el servicio doméstico, como planchadoras, criadas y lavanderas (Bravo y Teitelbaum, 2009, pp. 68-69).

15 Bravo, 2000, pp. 31-61. 
ratificaba la coacción de la fuerza de trabajo pero, a su vez, introducía algunas modificaciones importantes». En esa línea se situaron, por ejemplo, la inclusión de un monto salarial para ser excluidos de la categoría de vagos, la abolición de los castigos corporales como mecanismo correctivo y el establecimiento del descanso dominical, con excepción de las épocas de cosecha y del tipo de servicio. ${ }^{16}$

La abolición en 1896 de la «Ley De Conchabos» significó un cambio fundamental en las condiciones de trabajo. Sin embargo, como señala Bravo, la clausura de este régimen coactivo no trajo aparejada la transformación del resto de las modalidades laborales, como por ejemplo la duración de la jornada de trabajo. ${ }^{17}$ Por otra parte, resulta importante subrayar, según explica esta historiadora, que desde la derogación del conchabo en 1896 y hasta el año 1907 las iniciativas legislativas en materia laboral fueron prácticamente nulas. ${ }^{18}$ Este vacío legal en esa temática se cubrió indirectamente a través de las ordenanzas municipales. Así, durante este periodo, el accionar del Estado provincial en el terreno laboral se circunscribía a la vigilancia de los establecimientos mediante las inspecciones del Consejo de Higiene. La municipalidad, por su parte, establecía las normas sobre el funcionamiento de los servicios y establecimientos comerciales y productivos, con lo cual regulaba tangencialmente los oficios y ocupaciones urbanas. ${ }^{19}$

Tomando en cuenta estos señalamientos quisiera proponer que durante esta etapa inaugurada con la desaparición del conchabo obligatorio se fueron gestando los cambios que llevaron más tarde a la sanción de las primeras leyes sociales y laborales en la provincia. Las reivindicaciones y propuestas de las sociedades gremiales y de ayuda mutua, así como las cam-

16 Idem. No está de más anotar, tal como propone Campi, que si bien en el resto del territorio argentino en el siglo XIX se aplicaron mecanismos compulsivos similares, el caso tucumano presentaba características singulares debido a los atributos de Tucumán que, en contraste por ejemplo con la campaña de Buenos Aires y de Córdoba, no era un espacio de fronteras abiertas. «Tampoco ofrecía mayores posibilidades de acceder de alguna manera al usufructo de las tierras públicas. No era, menos aún, un territorio escasamente ocupado. Por el contrario, era la provincia argentina más densamente poblada y a un nivel excepcional. [...] Tucumán poseía, además, un sector agrícola-ganadero muy diversificado, con gran presencia de pequeñas y medianas explotaciones, lo cual otorgó a su evolución económica, social y política una singularidad que todavía conserva frente a las otras provincias noroestinas, la que, según observadores de la época, brindó durante el auge azucarero a industriales y grandes plantadores la posibilidad de apoyarse sobre un sector social de medianos y pequeños productores para solucionar el problema de la mano de obra.» (Campi, 1993).

17 Bravo, 2000.

18 Idem.

19 Bravo y Teitelbaum, 2009. 
pañas emprendidas por la prensa, revelan algunas de las prácticas emprendidas en esta dirección.

\section{El Orden y la cuestión social/obrera}

Una revisión de la prensa, en particular de El Orden, principal diario de Tucumán durante el periodo estudiado,$^{20}$ revela la influencia creciente que a finales del siglo XIX y especialmente al despuntar la nueva centuria, adquirió el tema del trabajo y los trabajadores. En sintonía con lo observado en otras provincias de Argentina, como Buenos Aires y Santa Fe, desde los primeros años del novecientos, a partir del crecimiento del conflicto social, entendido especialmente como obrero, ${ }^{21}$ los artículos publicados por este diario asignaron un espacio cada vez mayor a los problemas que afectaban al mundo laboral. Estos temas, abordados de forma sostenida, contribuyeron a delinear una agenda de denuncias y quejas sobre las deficientes condiciones de vida y de trabajo en Tucumán del entresiglo, en donde El Orden interpelaba a los particulares, pero sobre todo a las autoridades públicas, a revertir y mejorar la situación de las clases populares. ${ }^{22}$

Esta apreciación nos remite directamente al análisis de un tema central de este trabajo: la conformación de la cuestión social/obrera y el papel que desempeñó la prensa en este proceso. Pero antes de continuar con el análisis propiamente dicho resulta importante anotar que El Orden, fundado el 14 de noviembre de 1883 por el político y periodista tucumano Ernesto Colombres, fue no sólo el diario más importante en Tucumán durante la época revisada sino también el de más larga vida, ya que incluso aparecía en 1948, aunque muy disminuido. ${ }^{23}$ Con relación a su tenden-

20 De carácter vespertino, El Orden fue además la primera publicación que apareció desde sus inicios como diario, aunque no aparecía ni los domingos ni los días festivos. (García Soriano, 1972, pp. 30-39).

21 Suriano, 2004b, pp. 1-29. Rojkind, 2008/2009, p. 16.

22 Para este trabajo, examiné sistemáticamente los números de El Orden desde mediados de la década de 1890 a finales del año 1911. En esa fecha el diario cambió su formato: redujo su tamaño y aumentó el número de páginas.

23 Como señala García Soriano, en una vida de unos 65 años pasaron por sus columnas numerosos equipos de redactores y de periodistas. «Puede decirse que la historia del periodismo tucumano desde 1883 hasta 1930, periodo floreciente de este vespertino, está en sus columnas», afirma este autor, y añade que en sus páginas colaboraron los más destacados periodistas tucumanos y en sus columnas se debatieron todos los grandes problemas de la provincia (García Soriano, 1972, pp. 30-39). La importancia de El Orden, por su continuidad y pervivencia, se combinaba con su singularidad, ya que sin perder su matriz facciosa logró superar la efímera vida característica de la prensa del siglo XIX (Lenis y Hernández, 2008). 
cia política interesa subrayar que El Orden transitó de órgano de expresión que respaldaba al gobierno provincial a portavoz de la oposición. En el periodo que nos ocupa, es decir en los años del tránsito entre los dos siglos, el diario apoyó en una primera etapa al gobierno de Lucas Córdoba —entre 1895-1898 — y a su partido oficial «Unión Provincial» que respaldaba el mandato del presidente Roca. Entre 1901 y 1904, Córdoba volvió a gobernar la provincia. Sin embargo, como explica M.C. Bravo, hacia 1902-1903, se fracturó la «Unión Provincial», fuerza política que hasta entonces había sido hegemónica, y los escindidos crearon un nuevo partido, la «Unión Popular», integrado por la mayoría de los industriales azucareros enfrentados con el gobierno de Lucas Córdoba. Órgano de expresión de esta nueva corriente política fue $E l$ Orden, que recrudeció sus críticas al «luquismo», ${ }^{24}$ y se enroló abiertamente en la oposición al roquismo.

Resulta claro, entonces, que los intereses políticos motivaron buena parte de los discursos de El Orden. En particular, el propósito de impugnar al gobierno en un contexto tensado por la fractura del bloque dominante actuó como un detonante clave en sus denuncias y sus propuestas. Desde esa óptica podemos leer las reclamaciones y los apoyos que brindó este diario al mejoramiento de las condiciones de vida y de trabajo en la provincia.

Tal como se desprende de la documentación analizada, el hacinamiento habitacional, la insalubridad y la falta de higiene en los espacios laborales y de vivienda y la ausencia de servicios públicos en los barrios y lugares alejados del centro de la ciudad, en donde habitaban las clases populares, fueron algunos de los principales tópicos tratados en las páginas de El Orden, que exhortaba a los empresarios, y sobre todo a los gobernantes, a intervenir para mejorar estos defectos. Paralelamente, el diario cuestionó el oneroso costo de los alquileres y el aumento de los precios en los artículos de consumo, que afectaban en forma especialmente aguda a los sectores populares. También se apoyó en los datos obtenidos de las oficinas públicas del gobierno para advertir acerca del número de inmigrantes que llegaban a la provincia y de la necesidad de ofrecerles trabajo en los ramos que requerían mano de obra. A esta información se le sumaban las investigaciones y las notas sobre el aumento de la desocupación. ${ }^{25}$

24 Alusión directa a Lucas Córdoba. Sobre su gobierno y la ruptura del bloque hegemónico, véanse Bravo, 1991 y Bravo, 2004.

25 El Orden, 5/6/1900, 13/8/1901, 14/8/1901, 19/8/1901, 23/8/1901, 28/8/1901, 5/10/1901, 11/11/1901, 29/11/1901, 29/3/1902, 31/3/1902, 31/10/1902, 22/11/1902, 26/11/1902 y 4/12/1902. 
Respecto a las condiciones de trabajo en la ciudad de San Miguel de Tucumán, El Orden publicó numerosos artículos en los cuales cuestionaba la prolongada extensión de la jornada laboral, la insuficiencia de los salarios y el incumplimiento de los acuerdos patronales. Un renglón aparte dentro de sus críticas lo ocuparon las narraciones sobre la situación que afectaba a los peones y jornaleros que laboraban en los ingenios azucareros, localizados en el municipio capital y en las áreas rurales de la provincia, sobre todo en el departamento de Cruz Alta. Los defectos de insalubridad y falta de higiene en los espacios de vivienda y de trabajo, los abusos y el maltrato de los patrones, los problemas derivados de las deudas de jornales e insuficiencia de los mismos y la extensión abusiva de los horarios de trabajo formaban parte de las denuncias de este diario sobre los trabajadores del azúcar. En tal sentido, exigía al gobierno que interviniera para solucionar la perjudicial situación de los peones y jornaleros de los ingenios. ${ }^{26}$

En consonancia con las discusiones nacionales en materia de regulación del trabajo, El Orden acompañó sus críticas a la situación del trabajo y los trabajadores, tanto urbanos como rurales, con una serie de propuestas y de reclamos específicos. De esta forma, asignó un lugar prioritario a la defensa de una legislación protectora frente a los accidentes de trabajo, la reglamentación laboral de mujeres y niños en las fábricas, el derecho al descanso de los obreros un día a la semana y la importancia de edificar viviendas populares que se ajustaran a los cánones de la higiene y la modernidad. ${ }^{27}$ Por esta vía, El Orden se erigió en una voz clave que subrayaba la necesidad de promover una mayor intervención del Estado en el terreno laboral. Instando al gobierno a superar su pasividad en materia de legislación y protección al trabajo, lo exhortaba a ocu-

26 Por ejemplo, El Orden, 27/9/1899, 29/1/1903 y 19/3/1902. No está de más anotar que la dureza de los regímenes de trabajo en las empresas azucareras atrajo la atención no sólo de la prensa local sino también de los semanarios y diarios nacionales, que dedicaron abundantes artículos a denunciar la explotación obrera en los ingenios del Norte argentino, y particularmente de Tucumán. Más allá de los sesgos que podían revelar estos discursos acerca de la situación de los peones azucareros, lo que me interesa, en rigor, es apuntar que los mismos formaron parte de un tópico recurrente de políticos, intelectuales y líderes obreros, en particular de aquellos que militaban en las filas del socialismo y el sindicalismo.

27 Ibidem, 25/2/1901, 3/6/1902, 7/6/1902, 9/6/1902, 12/6/1902, 27/6/1902. A partir del año 1906, este diario dedicó un amplio espacio a denunciar el estado de las edificaciones que albergaban a las clases populares e inició una activa propaganda para reclamar la construcción de casas para obreros, tema estudiado antes en Teitelbaum, 2009. 
parse de la cuestión social y de una de sus aristas más visibles: la cuestión obrera. ${ }^{28}$

Finalmente, quisiera proponer que la atención concedida por el diario a los problemas que enfrentaban los trabajadores, así como la difusión de las principales propuestas para corregir y mejorar diversos aspectos vinculados con las condiciones de trabajo, deben enmarcarse en un clima político-ideológico que superaba el espacio acotado de la provincia. De hecho, este mismo tipo de discurso impregnaba las narraciones de la prensa en otros escenarios del país. En tal sentido, y como bien lo sugiere Suriano, «por sensibilidad social, por interés comercial o por oposición política a gobiernos de turno, es posible suponer que la prensa haya sido una de las principales demandantes de respuestas por parte del Estado para resolver diversos aspectos de la cuestión social». ${ }^{29}$

\section{Las sociedades de trabajadores y la prensa}

Tal como sucedía en la capital del país y en las principales provincias argentinas, al despuntar el siglo XX aumentó el protagonismo y visibilidad de los trabajadores en los espacios públicos de San Miguel de Tucumán y sus alrededores. En especial, el crecimiento del conflicto social y laboral de las clases trabajadoras ocupó un lugar destacado en la escena provincial e impactó en la opinión pública de la época. La lucha por reducir la jornada laboral, el reclamo por los salarios adeudados o demasiado bajos y la crítica a los malos tratos e incumplimiento de los acuerdos por parte de patrones, se inscribieron en el horizonte de protestas de los trabajadores que recurrieron a distintas estrategias de lucha, tales como los petitorios, las huelgas, las manifestaciones y los paros.

28 Ibidem, 19/3/1902, 4/8/1902, 22/11/1902 y 3/12/1902. En esa tónica, resultaron sugerentes los análisis de Agustina Prieto sobre el tratamiento de la prensa a la cuestión obrera en la ciudad de Rosario. Como señala esta historiadora, a finales de 1901 el incremento del conflicto obrero provocó el «descubrimiento» de la «cuestión obrera». Según Prieto, «tras el descubrimiento de la emergencia de esa particular faceta de la ‘cuestión social’, las masas obreras fueron objeto de un interés que excedió con creces la preocupación generada hasta entonces por sus supuestas proyecciones sobre el estado sanitario del conjunto de la población». En 1904, «los trabajadores tuvieron un protagonismo que los colocó de manera más contundente que en 1901-1902 en el centro de la escena pública. La prensa se abocó de lleno a la cuestión social hizo de las multitudes obreras uno de sus grandes temas» (Prieto, 2000, pp. 105-119).

29 Suriano, 2004b, pp. 33-58. 
En gran medida, estas prácticas provenían de las sociedades de trabajadores que se formaron especialmente entre 1895 y 1905. Durante una primera etapa que podemos situar aproximadamente entre los años 1895 y 1899, el grueso de las asociaciones de trabajadores se conformó bajo los principios del socorro y la ayuda mutua. A partir de este objetivo principal las sociedades contemplaron además un extenso abanico de actividades que variaban, por ejemplo, según el contexto de su surgimiento, la naturaleza de su conformación y el perfil de sus socios..$^{30}$

Dentro de la trama asociativa se destacaron las organizaciones católicas, en especial los círculos de obreros formados desde 1895, que desempeñaron un papel importante en la sociabilidad y cultura popular. Sin embargo, con la excepción del apoyo otorgado a los dependientes de comercio en su petitorio a favor del descanso dominical, los católicos no participaron activamente, al menos durante el periodo que recorre este trabajo, en las prácticas de protesta y lucha gremial. ${ }^{31}$

En 1899 se crearon asociaciones mutuales que reunieron a los trabajadores a partir de la localidad, como el Centro de Socorros Mutuos de Aguilares y el Centro de Trabajadores de Socorros Mutuos de Monteros. ${ }^{32}$ En esa fecha también se estableció la «Sociedad de Socorros Mutuos de Mujeres», auspiciada y dirigida por el Centro Cosmopolita de Trabajadores, ${ }^{33}$ institución forjada en 1897 que alcanzó un lugar destacado dentro de la constelación de organizaciones de trabajadores, al posicionarse como un lugar de encuentro clave para las prácticas de sociabilidad y cultura del mundo del trabajo. ${ }^{34}$ En efecto, un recorrido sistemático por las páginas de El Orden reveló la significativa presencia del Centro Cosmopolita de Trabajadores, que apoyó y promovió diversas actividades, como veladas, conferencias y festivales que desarrollaron los trabajadores $\mathrm{y},{ }^{35}$ asimismo, funcionó como el espacio articulador y coordinador de la mayoría de las demandas de las asociaciones obreras. A través de este centro obrero, los dirigentes provenientes del reformismo liberal y especial-

30 Al respecto, fueron iluminadores los trabajos de Hilda Sabato sobre las asociaciones en Argentina durante la segunda mitad del siglo XIX. En particular, Sábato, 2002, pp. 99-167.

31 Bravo y Teitelbaum, 2009.

32 Archivo Histórico del Tucumán, Sección Administrativa (en adelante AHT, SA), V. 255, 1899, V. 256, 1899 y V. 293, 1903.

33 Ibidem, V. 249, 1899.

34 Sobre la creación del Centro Cosmopolita de Trabajadores, El Orden, 3/11/1897 y desde el 28/10/1898 al 19/11/1898. 24/10/1906.

35 Ejemplos en ese sentido se pueden ver en los artículos de El Orden, desde el 3/11/1897 al 
mente del socialismo y el anarquismo - tendencias que no sin conflictos y tensiones convivieron en su interior- dedicaron sus esfuerzos a convocar y reunir en sus filas a un vasto y heterogéneo contingente del mundo del trabajo que utilizó sus recursos materiales y simbólicos en la lucha contra los patrones y poderes públicos.

Durante los primeros años del siglo XX, la participación de los líderes obreros vinculados al socialismo se incrementó en las actuaciones del Centro Cosmopolita de Trabajadores y esto se reflejó, por ejemplo, en las reiteradas visitas de dirigentes socialistas nacionales y algunos dirigentes extranjeros que llegaban a la provincia en giras de propaganda política. En ese marco cobraron vigor las asociaciones gremiales y de resistencia. Así, entre 1902-1903 y 1905 surgieron las sociedades gremiales de oficiales peluqueros cocheros, mozos de hoteles y confiterías, carpinteros y herreros y anexos. A su vez, se formaron las sociedades de albañiles y anexos y la de sastres, reorganizadas al poco tiempo como sociedades de resistencia. En ese periodo, también, se constituyó el gremio de panaderos, que reemplazó probablemente a la antigua Sociedad Protectora de Socorros Mutuos de Panaderos, creada en 1889. ${ }^{36}$

Estas asociaciones se reunían por lo general en el local del Centro Cosmopolita de Trabajadores. En 1904 se creó el Centro Socialista y, tal como se desprende de las fuentes consultadas, desde comienzos de 1905, especialmente a partir de mediados de ese año, las actividades sociales, culturales y gremiales de los trabajadores se realizaron desde ese ámbito cuya adhesión al partido socialista era manifiesta. ${ }^{37}$

Finalmente, quisiera mencionar el lugar destacado que ocupó en esta trama asociativa la Sociedad de Empleados de Comercio, creada en 1903 y refundada al año siguiente con el nombre de Unión Dependientes de Comercio. ${ }^{38}$ Esta asociación gremial y de socorro mutuo no integró el Centro Cosmopolita de Trabajadores ni posteriormente el Centro Socialista pero recibió el respaldo de dichos espacios obreros en las demandas que formuló, como la referida al descanso dominical que se analizará en el próximo apartado.

36 AHT, SA, V. 183, 1889.

37 Bravo y Teitelbaum, 2009.

38 Para 1905, la mayoría de los oficios y ocupaciones urbanas contaba con una sociedad gremial. Además de las mencionadas en el trabajo, otros gremios de trabajadores que se formaron en la ciudad de San Miguel de Tucumán durante el periodo señalado fueron, por ejemplo, las de mozos de mano; obreros municipales y empleados públicos. 
Pero antes de comenzar con el análisis propiamente dicho de esta temática me gustaría subrayar la importancia de la prensa como una de las principales fuentes de información sobre las prácticas asociativas. En particular, la lectura del diario El Orden permitió reconstruir el movimiento asociativo de los trabajadores, en la medida que sus páginas registraron sistemáticamente la conformación de mutuales, gremios y centros obreros. Asimismo, este diario publicó a lo largo del periodo estudiado artículos sobre las asambleas de socios que celebraban las sociedades, noticias acerca de las protestas y de los eventos recreativos y culturales que desarrollaron muchas de estas asociaciones e, incluso, notas que revelaban los conflictos y tensiones que podían desplegarse al interior de estos espacios.

Como ya ha sido señalado por la bibliografía sobre el tema, tanto para Argentina como para otros países de America Latina, durante el periodo se produjo una estrecha ligazón entre la prensa y las asociaciones que utilizaron sus columnas para publicitar y fomentar sus actividades. Por su parte, la prensa, sobre todo aquella que respondía a los principios liberales de la época, instaba a los trabajadores a movilizarse y enfatizaba la importancia de la asociación en el mundo laboral..$^{39}$ No me voy a detener mucho más en este punto. Solamente quisiera sugerir que este vínculo no resulta tan extraño si tenemos en cuenta las transformaciones que desde mediados del siglo XIX experimentaba el ámbito periodístico. Los diarios se posicionaron como foros claves de la expresión y construcción de ideas y, junto con las instituciones surgidas en el seno de la sociedad civil, como clubes y asociaciones, contribuyeron a forjar una opinión pública cada vez más insoslayable. ${ }^{40}$ En ese contexto, las asociaciones de trabajadores eran percibidas por un amplio sector del mundo público como espacios de aprendizaje de prácticas cívicas y valores morales.

De acuerdo con estas consideraciones podemos interpretar los discursos de El Orden, que exhortaba a los trabajadores a participar y aunar sus esfuerzos para formar sociedades, percibidas como lugares propicios para la moralización y el desarrollo de hábitos democráticos. En especial, el diario destacaba la importancia de las asociaciones gremiales al considerarlas una vía eficaz para luchar por derechos y mejoras laborales.

39 En tal sentido, fue muy sugerente el análisis de Di Stefano, 2002, pp. 23-97. Para otros contextos latinoamericanos, me permito citar el trabajo sobre las asociaciones de trabajadores en México, en especial, Teitelbaum, 2008.

40 Teitelbaum y Gutierrez, 2008a, pp. 127-158 y 2008b, pp. 587-605. 


\begin{abstract}
Nuestro diario ha exhortado siempre a las clases obreras a formar asociaciones gremiales que sean una garantía contra los abusos de los patrones y presten el apoyo colectivo a los asociados que se resistan a sufrir las arbitrariedades y tiranías en las fábricas o talleres.

Desgraciadamente el espíritu de asociación no ha tomado aún, entre nosotros, el desarrollo que alcanza en los países europeos y en las mismas ciudades del litoral. Nuestros obreros proceden, por lo general, individualmente, esterilizando así sus esfuerzos cuando quieren defender sus derechos. ${ }^{41}$
\end{abstract}

A pesar de esta crítica sobre el desinterés y escaso desarrollo del movimiento asociativo de los trabajadores en la provincia, el diario mencionaba en ese mismo artículo publicado en 1903 algunos casos que debían «servir de ejemplo y estímulo a los trabajadores», como los peluqueros y más tarde los tipógrafos, quienes fueron «iniciadores de un movimiento simpático en defensa de sus intereses» y habían constituido un poderoso gremio para defenderse de los abusos de sus patrones. ${ }^{42}$

Dos consideraciones. Por un lado, no estaba tan equivocado el diario en sus quejas si tenemos en cuenta que fue a partir de 1902, pero especialmente entre 1903 y 1905, cuando adquirió mayor impulso la formación de asociaciones gremiales en el mundo del trabajo. Por otro lado, y si bien dejaba fuera de su narración algunas otras muestras relevantes del accionar de los trabajadores en favor de sus derechos, tenía razón al destacar la importancia de peluqueros y tipógrafos en el horizonte de prácticas asociativas y de protesta gremial, ya que estos fueron muy activos en la época bajo estudio en la lucha por mejorar sus condiciones de trabajo. Tal como se desprende de la documentación revisada, los tipógrafos conformaron en 1893 una de las primeras sociedades de trabajadores de Tucumán sobre las cuales tenemos noticias, la Sociedad Unión Tipográfica, que llegó a ser una de las sociedades de oficio más prestigiosas de la época; incluso fue una de las pocas asociaciones de trabajadores que consiguió fundar un periódico propio y realizó esfuerzos a favor de establecer un panteón. Asimismo, la sociedad de los tipógrafos organizó abundantes veladas de recreación y cultura, al tiempo que impulsó distintas protestas contra los patrones y poderes públicos ${ }^{43}$ Sobre los peluqueros trataré en el siguiente apartado.

41 El Orden, 9/6/1903.

42 Idem.

43 AHT, SA, V. 206, 1894. El Orden, 4/3/1903. 


\section{Las campañas a favor del descanso dominical}

Al igual que sucedía en otras provincias argentinas, dentro de los conflictos obreros desarrollados en Tucumán a lo largo de la primera década del XX una de las demandas más fuertes fue la del descanso dominical. Esta reclamación aglutinó a numerosos gremios de trabajadores y contó con el apoyo de la prensa, que avaló y fomentó estas iniciativas. ¿Cómo se consiguió el descanso dominical?, ¿cuál fue el itinerario recorrido para alcanzar la sanción de la ley? y ¿qué alcance tuvo la misma?, fueron algunas de las inquietudes surgidas al analizar esta temática hasta ahora muy poco transitada por la historiografía provincial. Sin la pretensión de agotar el tema con estas páginas, quisiera destacar que fueron las sociedades gremiales y mutuales, como la de peluqueros y, más tarde, los dependientes de comercio, quienes iniciaron la demanda por el descanso hebdomadario desde comienzos del novecientos.

En marzo de 1902 los oficiales peluqueros se reunieron en el Centro Cosmopolita de Trabajadores con el fin de formar una sociedad de socorros mutuos y de resistencia. El objetivo principal de esta asociación era conseguir medidas favorables al gremio, tal como el cierre de las peluquerías los domingos en el perímetro de cuatro cuadras de la plaza Independencia (principal paseo público de la ciudad de San Miguel de Tucumán en la época estudiada). Esta iniciativa contó con el respaldo de El Orden, que exhortó a los patrones a adoptar dicha resolución al asegurar que la misma no podía perjudicarlos en tanto el cierre de los locales fuera general.

Paralelamente, el diario convocó a los trabajadores que laboraban como dependientes de comercio a sumarse a la campaña que se llevaba a cabo en Buenos Aires a favor del descanso dominical. Con el fin de apoyar el meeting y el petitorio al Congreso que estaban organizándose en la capital del país, puso sus columnas a disposición de los trabajadores de Tucumán. Pero esta invitación no contó con la recepción esperada y, tal como reclamaba esta fuente, los apoyos se manifestaron únicamente en algunas casas de comercio que comenzaron a reducir sus horarios de trabajo, cerrando sus locales a las ocho de la noche para brindar descanso a los empleados y disminuir las horas de labor. ${ }^{44}$

En octubre de 1902 los esfuerzos de los peluqueros cristalizaron en la conformación definitiva de una sociedad gremial que reunía en su interior

44 El Orden, 5/3/1902, 16/4/1902, 20/8/1902, 23/8/1902, 16/10/1902 у 22/10/1902. 
a oficiales y patrones con la consigna central de luchar por la defensa de sus intereses comunes. En esa dirección, buscaban adoptar todas las medidas que pudieran beneficiar a los trabajadores de peluquerías, a los dueños de los locales y a sus clientelas, tal como era — argumentaban- el cierre dominical a las 12 horas de ese día. Para ampliar y fortalecer su reclamo, la Sociedad de peluqueros decidió incluir en su petición a los ramos de bazar y sombrerería. Asimismo, resolvió dirigir una nota al Consejo Deliberante, por intermedio del intendente de la municipalidad, en donde solicitaba la ordenanza de descanso dominical. Posteriormente, los comerciantes minoristas de tienda se sumaron a esta campaña y enviaron una nota al Consejo Deliberante en la misma línea que los peluqueros. ${ }^{45}$

Presentado así mismo como el principal impulsor de la campaña por el descanso dominical, El Orden elogiaba el respaldo obtenido en toda la provincia al asegurar que no sólo en la ciudad de San Miguel de Tucumán, sino también desde el interior, llegaban evidencias de participación y apoyo a esta demanda. Por ejemplo, los dependientes de comercio de Lules se habían dirigido por escrito al diario para adherirse a la solicitud de sus colegas capitalinos y pedirle que activara su propaganda en la campaña, en donde, según aseguraban los trabajadores, «no hay humanidad por parte de nuestros patrones, quienes por lucrar más no cierran sus puertas los días domingos y festivos ni uno solo durante el mes».

En ese contexto, y como la resolución del Consejo Deliberante favorecería únicamente a los empleados de comercio del municipio capital, El Orden explicaba la necesidad de extender los beneficios de esta medida a las villas de campaña, ya que allí, la «tiranía del mostrador es aún más terrible que en esta capital», decía en una clara sintonía con las palabras utilizadas por los dependientes de Lules. Para alcanzar este propósito, exhortaba a los trabajadores a formar una asociación gremial que reuniera a los dependientes de comercio de la ciudad de San Miguel de Tucumán y a los de la campaña. De esta forma, lograrían unificar sus reivindicaciones y solicitar a los patrones y a las autoridades las medidas más justas. ${ }^{46}$ Esta propuesta, formulada a partir de una consideración compartida por diversos sectores de la época que sostenía que los trabajadores debían luchar por sus derechos y no esperar en cambio recibir todo ya hecho, revelaba la importancia asignada por el diario a la protesta obrera a través de los gremios.

45 Ibidem, 23/10/1902, 25/10/1902, 27/10/1902 у 28/10/1902.

46 Ibidem, 18/11/1902. 
Dos años después, el anhelo de El Orden de integrar a los dependientes de comercio de Tucumán en una misma asociación fue parcialmente cumplido. Así, a mediados de 1904, el diario registró en sus columnas que los dependientes de comercio de las ciudades de Monteros, Concepción y otros puntos de la provincia habían enviado cartas para solicitar el ingreso a la Unión Dependientes de Comercio de San Miguel de Tucumán y destacar al mismo tiempo su adhesión a la campaña por el descanso dominical. ${ }^{47}$

Estas muestras de respaldo formaron parte de la influencia que adquirió para entonces la lucha por ese descanso hebdomadario. Retomaré este tema un poco más adelante en este mismo apartado. En este momento me interesa señalar que finalmente, las Ordenanzas municipales sobre el cierre dominical se dictaron y el 21 de noviembre de 1902 El Orden anunció que las mismas entrarían en vigencia el domingo siguiente. La pena prevista para los infractores era una multa de 50 pesos la primera vez y de 100 pesos en las siguientes. ${ }^{48}$

Al despuntar el año 1903, por su parte, los dependientes de comercio mayorista iniciaron sus trabajos para conseguir esta resolución, llegando a un acuerdo con los patrones para no abrir las casas de comercio los domingos y festivos. Por otra parte, en el interior de la provincia también se evidenciaban adelantos en favor del descanso dominical. Tal fue el caso de lo sucedido en Monteros, cuando el gobierno municipal dictó una Ordenanza para ofrecer este beneficio al gremio de dependientes de comercio. Esa medida, por supuesto, contó con los elogios de El Orden que, en una suerte de síntesis de su postura con relación al tema que nos ocupa, afirmaba: «la intervención de los poderes públicos en la reglamentación del trabajo, es una de las principales conquistas que nos ha legado las postrimerías del siglo XIX y obtendrá su completa sanción en la presente centuria». ${ }^{49}$

Pero más allá de estos avances, lo cierto fue que las ordenanzas municipales y los acuerdos conseguidos con los patrones no siempre se respetaban. En ese contexto, El Orden se hizo eco de los reclamos de los trabajadores advirtiendo acerca del incumplimiento por parte de algunos propietarios de la normativa y de los acuerdos para cerrar las casas de comercio en los horarios y días estipulados.

Paralelamente, los trabajadores, con el apoyo del diario, canalizaron sus esfuerzos para alcanzar la sanción de una ley de descanso dominical

47 Ibidem, 9/6/1904 y 10/6/1904.

48 Ibidem.,21/11/1902.

49 Ibidem, 10/1/1903 y 13/1/1903. 
por parte del Ejecutivo provincial. Así, durante el año de 1904, al calor del crecimiento y consolidación de la sociedad Unión Dependientes de Comercio, presentaron un proyecto de ley a la Legislatura. ${ }^{50}$ Esta petición contaba con la aprobación de la mayoría de los patrones. ${ }^{51}$ Además, los dependientes de comercio habían realizado gestiones para conseguir el apoyo de grupos católicos a través de notas dirigidas al Obispado y a los padres franciscanos y dominicos. También buscaron el aval de la Sociedad Sarmiento, espacio clave de la difusión de ideas liberales y principal asociación cultural del periodo estudiado. ${ }^{52}$

Dos años después, sin embargo, el proyecto seguía sin resolverse. En consecuencia, apoyándose en los adelantos conseguidos por la capital argentina, que había sancionado en agosto de 1905 la ley de descanso dominical, ${ }^{53}$ la Unión Dependientes de Comercio envió en abril de 1906 una solicitud a la Cámara de diputados de Tucumán para que incluyera en sus sesiones extraordinarias el proyecto presentado sobre descanso dominical que se encontraba en las Cámaras para su sanción definitiva. ${ }^{54}$ Pero la ley continuaba sin dictarse. En ese marco, El Orden publicó en noviembre de ese año un artículo titulado «Legislación obrera», en el cual exhortaba a los legisladores a activar el tratamiento de los aspectos relacionados con la cuestión obrera y sancionar las leyes necesarias para favorecer a los trabajadores, dentro de las que se encontraba la del descanso dominical. ${ }^{55}$

Para concluir, interesa señalar que, de forma similar a lo que sucedía en otras provincias del país, la reivindicación del descanso hebdomadario concitó la atención pública sobre todo en los momentos de su discusión legislativa. ${ }^{56}$ Sin embargo, y como sostiene Ricardo Falcón en su trabajo

50 Ibidem, 21/9/1904.

51 Ibidem, 18/6/1904.

52 Ibidem, 20/871904.

53 Ibidem, 25/8/1905. Esta ley presentada en la Cámara de Diputados de la Nación por el socialista Alfredo Palacios, se promulgó tras duros debates acerca de su alcance y sobre el pago del sueldo o jornal de ese día. Como señala Alejandra Landaburu, la ley contó con los elogios del diputado tucumano Ernesto Padilla, representante de las elites azucareras y futuro gobernador de la provincia (Landaburu, 2005).

54 El Orden, 20/4/1906.

55 Ibidem, 6/11/1906.

56 En tal sentido, y como señala Ricardo Falcón para la ciudad de Rosario, dos momentos fuertes de estos reclamos tuvieron lugar en 1904 - en consonancia con las discusiones generadas alrededor del proyecto de Código de Trabajo y luego en torno a la sanción de una ley sobre descanso dominical para la Capital Federal- y 1906, en el marco de la sanción de una ley similar en la provincia de Santa Fé (Falcón, 2005, pp.77-78). La reivindicación del descanso dominical en Rosario puede verse también en el estudio de Prieto, 2000, pp. 110-111. Para Neuquén, Mases, Frapiccini, Rafort y Lvovich, 1994, pp. 88-90. 
sobre la ciudad de Rosario, en la práctica, «al margen de las disposiciones legales, el descanso dominical se fue imponiendo a través de convenios particulares de distintos gremios». De esta forma, y a pesar de la oposición de algunos comerciantes, sobre todo de los propietarios de locales que consideraban perjudicial el cierre de sus establecimientos los domingos cuando podían engrosar sus ganancias (por ejemplo los dueños de cafés y restaurantes), el descanso semanal que había sido «impulsado originariamente por el movimiento obrero, será luego aceptado por la mayoría de los empresarios y por los poderes públicos». ${ }^{57}$

En gran medida, estas consideraciones pueden aplicarse para el caso de Tucumán, en donde finalmente el respaldo de los propietarios a la reclamación por el descanso dominical fue clave para alcanzar la concreción de esta medida. Aunque todavía quedan diversos aspectos que explorar sobre esta temática, me interesó destacar en estas páginas el papel desempeñado por la prensa, en particular por el diario El Orden, que avaló y fomentó las iniciativas de los gremios en su lucha por alcanzar este derecho. En tal sentido, argumento, las prácticas de protesta desarrolladas por las sociedades gremiales y mutuales de trabajadores, en articulación con la prensa, ocuparon un lugar central en el camino hacia la legislación laboral.

\section{7: sanción de la ley, festejos y movilización}

El 22 de julio de 1907 el poder ejecutivo provincial sancionó la ley de descanso dominical y unos días después, el 25, la promulgó. ${ }^{58}$ De acuerdo a lo previsto, la ley tenía que entrar en vigencia en la segunda quincena de agosto, contexto en el cual se desarrolló el meeting organizado por El Orden y los dependientes de comercio para festejar la promulgación de esa ley. Esta reunión tuvo lugar en San Miguel de Tucumán el día 25 de agosto y comenzó con las palabras del secretario de la Unión Dependientes de Comercio. Posteriormente se oyeron los discursos de renombrados líderes obreros locales, como el tipógrafo Daniel Villagrán y dirigentes del Centro Socialista, como Horacio Stabile y Antonio F. López. También hablaron en esa reunión los representantes de la sociedad de obreros peluqueros. Según aseguraba el diario, todos los oradores fueron

57 Falcón, 2005, pp.78-79.

58 La Legislación laboral en Tucumán, 1969, p. 245. 
muy aplaudidos por los numerosos gremios de trabajadores que se dieron cita en la celebración. ${ }^{59}$

De acuerdo con el decreto del 7 de agosto que reglamentaba la ley de descanso dominical, quedaban excluidos de este beneficio los trabajadores de establecimientos que vendían artículos de primera necesidad — restaurantes, fondas y casas de comida-, los que laboraban en mercados de comestibles y puestos de carne, aves, pescados, legumbres, frutas, carbón y leña, los ocupados en tambos y lecherías, los empleados de almacenes que vendían exclusivamente comestibles, los trabajadores de fiambrerías, pastelerías, bombonerías, confiterías, dulcerías, chocolaterías, casas expendedoras de café y boticas. Asimismo, se prohibía el descanso dominical para el reparto de carne, pan, leche, hielo, etc. ${ }^{60}$

Los límites establecidos por la ley, que circunscribía a un segmento muy específico de trabajadores el beneficio de este derecho, generaron protestas y movilizaciones. En ese contexto se situó la huelga de los oficiales panaderos declarada a comienzos de septiembre de ese año. Según advertían estos trabajadores, el artículo 2. ${ }^{\circ}$ de la ley estipulaba que, en caso de trabajar los obreros o dependientes el domingo, les sería compensado ese día con otro de la semana. En ese marco, ellos reclamaban un aumento del sueldo para costear por su cuenta un reemplazante durante los días previstos por la ley de descanso dominical. Tal como aseguraban los panaderos, el incremento del salario les permitiría disfrutar del beneficio de la ley y llegar a un acuerdo con los patrones, en tanto tenían previsto discutir y acordar para darse el descanso entre todos con tal de no suspender el trabajo. Este argumento, vertido en un pliego que entregaron a los patrones, fue al parecer exitoso; en el transcurso del conflicto los huelguistas recibieron el apoyo de los panaderos del interior -Concepción, Lules y San Pablo- y, al parecer, la huelga terminó con un acuerdo parcial entre las partes. ${ }^{61}$

Unos días después, la Federación Obrera local, de impronta anarquista, y la Confederación del Trabajo en Tucumán, encuadrada dentro de los postulados del socialismo, organizaron un meeting para apoyar la ley vigente de descanso dominical y pronunciarse en contra del decreto reglamentario que restringía el alcance de esta medida. ${ }^{62}$ La convocatoria reali-

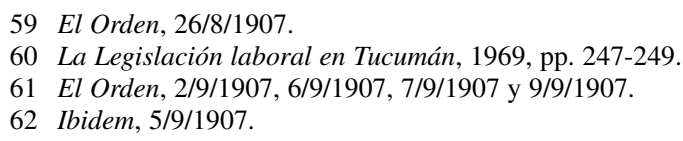


zada por esas organizaciones logró gran repercusión entre las sociedades gremiales de la provincia. Así, comprometieron su participación los gremios de dependientes de comercio, panaderos, mozos, sastres, peluqueros, alpargateros, carpinteros, albañiles, constructores de carruajes y ferrocarrileros. Asimismo, se adhirieron la sociedad de dependientes de comercio de las ciudades de Monteros y de Concepción. ${ }^{63}$

El resultado fue una amplia movilización en los espacios públicos de la ciudad de San Miguel de Tucumán que comenzó con la reunión de los trabajadores en la plaza La Madrid, en donde impartieron discursos algunos dirigentes obreros. Luego, los manifestantes recorrieron las calles acompañados de una bandera roja y una pequeña banda de música y posteriormente se detuvieron en distintos puntos del centro de la ciudad para escuchar las palabras de otros representantes de las sociedades gremiales. Según narraba El Orden, los trabajadores recibieron el aplauso de los habitantes que los saludaban desde los balcones, puertas y veredas. Tal como estaba previsto en la organización de esa reunión, el recorrido concluyó frente al local del sindicato de mozos, en donde habló uno de los dirigentes de la Federación Obrera local, Tomas Delgado, ${ }^{64}$ un conocido líder de las prácticas anarquistas en la provincia, ${ }^{65}$ así como el autor de la única publicación libertaria sobre la cual tenemos noticia para el periodo revisado. ${ }^{66}$

Finalmente, la columna de manifestantes se disolvió y una comisión de trabajadores se dirigió a la legislatura para entregar a los diputados una nota en donde solicitaban el mantenimiento de la ley vigente de descanso dominical. Asimismo, pedían que se conservara la disposición prevista en dicha ley según la cual se prohibía la venta de bebidas alcohólicas los domingos y días de fiesta. De acuerdo con la sociedad Unión Dependientes

63 Ibidem, 7/9/1907.

64 Ibidem, 6/9/1907, 7/9/1907 y 9/9/1907.

65 De acuerdo con la lectura sistemática de la prensa provincial disponible para el periodo 1895-1911, una de las pocas evidencias sobre el accionar anarquista en Tucumán fue la velada y conferencia dedicada a las clases trabajadoras que se desarrolló en el Teatro Belgrano unos días después de la movilización por el descanso dominical. Este acto, de carácter libertario, fue organizado por la Federación Obrera Local y comenzó con las palabras de Tomás Delgado. Posteriormente, se presentaron el Coro de la Federación y el Orfeón Libertario. La velada contó también con declamaciones y poesías, así como con los discursos de dirigentes provinciales y delegados de la Federación Obrera Regional Argentina (FORA), de naturaleza anarquista. Al respecto, Ibidem, 27/9/1907.

66 Tal como propone Santiago Bilbao, Tomas Delgado fue probablemente el único autor de los artículos que salieron en el número único de la revista Germinal, publicación que apareció el 1 de mayo de 1908 editada por la Federación Obrera Local Tucumán (Bilbao, 2004, pp. 143-151). Según la investigación que realicé hasta este momento, esta revista constituye una de las escasísimas referencias existentes sobre las prácticas anarquistas en Tucumán durante la época estudiada. 
de Comercio, que se adjudicaba la representación de todos los gremios y del «pueblo obrero en general», esta medida era completamente favorable porque contribuiría a disminuir la ebriedad que afectaba a los obreros y a sus familias, especialmente en algunas poblaciones del interior de la provincia, en donde — argumentaba — era también la causa de delitos. «Se ha visto por primera vez en Tucumán en las plazas públicas obreros acompañados de sus familias, reemplazando la taberna con el paseo honesto», señalaban los dirigentes de esta asociación. ${ }^{67}$

Aunque este tema escapa ya a los fines propuestos en el trabajo, interesa mencionar que las expresiones que destacaban el compromiso de los trabajadores con el comportamiento basado en el honor y la moral se relacionan estrechamente con los reglamentos de las asociaciones mutuales de trabajadores que repudiaban el ejercicio de hábitos deshonestos y desarreglados, como la embriaguez y las riñas, considerados motivos de expulsión de los socios y de exclusión de cualquier beneficio del socorro y la asistencia médica. ${ }^{68}$

En fin, las campañas a favor del descanso dominical reunieron a los trabajadores en un amplio movimiento de protesta que incluyó peticiones a los patrones, solicitudes a las autoridades, notas de adhesión en la prensa, manifestaciones y huelgas. En ese contexto, y tal como intentó exponer, la reclamación iniciada hacia 1902 por las sociedades de peluqueros y de empleados de comercio articuló la movilización de la mayoría de las asociaciones gremiales y mutuales de la provincia en los momentos de sanción y reglamentación de la ley, en 1907, cuando los trabajadores de las distintas corrientes que organizaban el mundo laboral, como el socialismo y el anarquismo, se dieron cita en los espacios públicos de la ciudad.

Para concluir, quisiera agregar que la ley 923 de descanso dominical de 1907, si bien restringía el beneficio de este derecho a un segmento del mundo del trabajo, fue la primera ley específicamente laboral. Hasta el año 1923 no se sancionaron y promulgaron otras leyes laborales: la ley 1346, que establecía la jornada máxima de trabajo, y la ley 1348 del salario mínimo. ${ }^{69}$ Pero la sanción de la ley de descanso dominical no fue tampoco un hecho aislado; formaba parte de las propuestas difundidas entonces para

67 El Orden, 9/9/1907.

68 A modo de ejemplo, se pueden mencionar el Reglamento de la Sociedad de Panaderos de 1889 y los Estatutos de 1899 de la Sociedad Argentina de Socorros Mutuos de Obreros, institución nacida en 1877 (AHT, SA, V. 183, 1889 y V. 255, 1899).

69 La Legislación laboral en Tucumán, 1969, pp. 245-251. 
mejorar la situación de los trabajadores en un contexto signado por el ascenso de los representantes del reformismo social a posiciones legislativas. En tal sentido, resulta importante mencionar la inclusión de un artículo en la Constitución provincial de 1907, por el cual se obligaba a la Legislatura a reglamentar el trabajo de la mujer y los menores en las fábricas y otros establecimientos laborales. ${ }^{70}$ En esa fecha también se dictaron leyes sociales, como la del Monte Pío Civil, que en el marco de la Seguridad Social establecía un fondo de jubilaciones y pensiones para los funcionarios, empleados y agentes civiles de la administración, ${ }^{71}$ y la ley de Amparo del Hogar, por la cual se declaraban exentas del pago de contribuciones las pequeñas y medianas propiedades..$^{72}$

\section{Consideraciones finales}

Fue en torno del 1900, al calor del crecimiento de la protesta social, especialmente laboral, cuando la «cuestión obrera» cobró influencia y visibilidad en el espacio público. En ese contexto, y en sintonía con lo que sucedía en Buenos Aires y en otros puntos del país, el diario El Orden exhortaba a la sociedad y, principalmente, al gobierno, a atender diversos aspectos relacionados con las deficientes condiciones de vida que afectaban a los grupos populares. La carestía de vida, el incremento de los alquileres, el aumento en los precios de los artículos de consumo, el hacinamiento habitacional y la precariedad e insalubridad de las viviendas recorrieron así las páginas del diario que clamaba por la intervención de quienes, se entendía, debían ocuparse de resolver y corregir estos problemas sociales.

A su vez, un conjunto extenso de tópicos que aludían específicamente a las condiciones de trabajo formaron parte también de las narraciones de El Orden, que publicó abundantes artículos, investigaciones y crónicas para denunciar la desocupación, la explotación del trabajo obrero en los ingenios, la extensión excesiva de la jornada laboral, la debilidad de los salarios y el incumplimiento de los acuerdos patronales.

70 Bravo, 2004, pp. 56-58.

71 Idem. De esta forma, y tal como la autora citada señala, se beneficiaba a un sector importante de los trabajadores urbanos, sobre todo de la ciudad de San Miguel de Tucumán, que concentraba el mayor número de personal del Estado.

72 Ibidem, p. 58. Con lo cual se favorecía, de acuerdo a Bravo, «a una franja de propietarios humildes, que sólo incluía a un segmento del artesanado urbano y a los pequeños propietarios rurales». 
Revertir este cuadro desfavorable de la situación de los trabajadores implicaba que el gobierno debía asumir un papel más activo en el terreno laboral y, en esa dirección, establecer instituciones y leyes específicas. De acuerdo con estas consideraciones, y en consonancia con los debates de carácter nacional que tenían lugar, el diario difundió los pasos emprendidos a favor de la reglamentación del trabajo, especialmente de mujeres y niños, el dictado de una legislación sobre accidentes de trabajo, la sanción del descanso dominical y la construcción de viviendas obreras. En ese contexto, exhortaba al gobierno de Tucumán y a los trabajadores a respaldar y favorecer estos avances en el ámbito provincial. En especial, durante el periodo que recorre este trabajo, asignó un lugar destacado a la demanda por el descanso dominical, un reclamo prioritario de los trabajadores en la primera década del siglo $\mathrm{XX}$.

Como vimos, desde 1902 y hasta su sanción como ley en el año 1907, las sociedades de peluqueros y empleados de comercio encabezaron las demandas a favor del derecho hebdomadario. El Orden respaldó sus reivindicaciones y acompañó mediante una cobertura sostenida las distintas estrategias a las que recurrieron los trabajadores para alcanzar este derecho, tales como las solicitudes enviadas al Consejo Deliberante para que dictara las ordenanzas municipales sobre el descanso dominical y las demandas realizadas a los diputados provinciales con el fin de acelerar la sanción de la ley.

Definido así mismo como el principal impulsor de la campaña por el descanso dominical, El Orden publicó numerosos artículos que subrayaban la importancia de este derecho y, al mismo tiempo, instaban a los gremios de trabajadores, a los propietarios de los establecimientos comerciales y de servicio, y primordialmente al gobierno, a respaldarlo. Según sus concepciones en torno al papel del Estado y de los trabajadores frente a la cuestión social, y en especial laboral, tres instancias eran claves. Por un lado, los trabajadores debían organizarse y luchar por sus derechos y, en ese sentido, la defensa de los intereses obreros mediante asociaciones gremiales era fundamental. De acuerdo con estas consideraciones, podemos interpretar el impulso que otorgó el diario a la formación de asociaciones en el mundo del trabajo, percibidas como herramientas claves para la defensa y el adelanto de los trabajadores. Por otro lado, era necesaria la participación activa de quienes regían los destinos de la provincia y, en esa dirección, demandó a las autoridades la elaboración y sanción de leyes e instituciones tendientes a mejorar las condiciones de vida y de trabajo. En esos parámetros podemos situar los reclamos del El Orden para que el gobierno pro- 
mulgara la ley de descanso dominical y la promoción y el apoyo otorgado a la lucha gremial a favor de este derecho. Finalmente, era importante, según el diario, conseguir el compromiso de otros actores sociales, especialmente de los grupos propietarios y patrones. Es decir, los dueños de los locales tenían que apoyar estos temas y cumplir los acuerdos y la normativa correspondiente al descanso dominical.

Los festejos que trajo aparejada la sanción de la ley de 1907, así como la movilización originada a partir de los descontentos frente al decreto reglamentario que restringía el alcance de este beneficio a un segmento del mundo laboral, recibieron los apoyos de El Orden, lo cual no resulta nada extraño teniendo en cuenta su promoción constante al establecimiento del descanso dominical. Por otro lado, y tal como se infiere de la documentación analizada, podemos proponer que la movilización del año 1907 se erigió en un momento clave de las prácticas de los trabajadores y reveló la visibilidad y organización que adquirieron entonces estos grupos. En primer lugar, el meeting organizado por el diario y los dependientes de comercio en agosto de ese año, reunión en la cual participaron también los peluqueros y el Centro Socialista, evidenció las estrechas vinculaciones entre las asociaciones a partir de una demanda articuladora. Unos días después, en septiembre del mismo 2007, las organizaciones que reunían a los trabajadores bajo la impronta del anarquismo y el socialismo, como la Federación Obrera local y la Confederación del Trabajo en Tucumán, convocaron también a una reunión pública con el doble objetivo de expresar, por un lado, el apoyo a la ley de descanso dominical y, por el otro, repudiar el decreto reglamentario que acotaba el beneficio de este derecho. Estas consignas, que lograron movilizar a un numeroso contingente de asociaciones obreras de la capital y del interior de la provincia, las cuales acudieron a los espacios públicos de San Miguel de Tucumán para participar del meeting, demostraron también la vinculación entre los gremios tucumanos y permitieron entrever la presencia de un movimiento obrero que había transitado un itinerario de crecimiento y organización a lo largo de la primera década del siglo XX.

Dos breves reflexiones para concluir. La primera tiene que ver con la importancia de la prensa como fuente y, especialmente, como un actor destacado en los procesos de construcción de la cuestión social y obrera. Como se intentó exponer en estas páginas, según el diario El Orden, el mejoramiento de las clases trabajadoras sólo podía lograrse mediante el compromiso de los actores sociales involucrados. En esa tónica, interpeló 
a los sectores empresariales y propietarios, reclamó respuestas por parte del Estado y alentó a los mismos trabajadores a fortalecer y unificar sus esfuerzos para alcanzar una respuesta satisfactoria frente a sus demandas laborales. En el caso puntual del descanso dominical revisado en este estudio otorgó un lugar prioritario al Estado, al reclamar la promulgación de disposiciones y leyes específicas dirigidas a mejorar la situación en el trabajo. En segundo lugar, quisiera sugerir que el reconocimiento del derecho al descanso dominical, si bien no alcanzó a la fuerza laboral en su conjunto, constituyó un primer paso en el itinerario complejo y no exento de contradicciones que implicó el camino hacia la legislación laboral.

Recibido el 13 de octubre de 2009 Aceptado el 04 de abril de 2011

\section{Bibliografía}

Armus, Diego: «Consenso, conflicto y liderazgo en la lucha contra la tuberculosis, Buenos Aires, 1870-1950», en Suriano, Juan (comp.): La cuestión social en Argentina, 1870-1943, Buenos Aires, La Colmena, 2004a, 191-216.

Bilbao, Santiago: «Anarquismo en el noroeste a principio del siglo XX: Germinal, publicación tucumana», Estudios del Trabajo, 28, Buenos Aires, juliodiciembre de 2004, 143-151.

Boletín de la Oficina de Estadística y del Trabajo de la Provincia de Tucumán, 1, Buenos Aires, Compañía Sudamericana de Billetes de Banco, 1914.

Bravo, María Celia: «Las leyes machete y la ruptura del frente azucarero tucumano», en Campi, Daniel (comp.): Estudios sobre la historia de la industria azucarera argentina, Jujuy, UNT-UNJU, 1991, 97-138.

Bravo, «Liberales, socialistas e Iglesia frente a la situación de los trabajadores en Tucumán», Suriano (comp.): La cuestión social en Argentina, 1870-1943, 2004a, 31-61.

Bravo, Campesinos, azúcar y política. Cañeros, acción corporativa y vida política en Tucumán (1895-1930), Rosario, Prohistoria Ediciones, 2008.

Bravo, María Celia y Teitelbaum, Vanesa: «Socialistas y católicos disputando el mundo los trabajadores. Protesta, sociabilidad y política en Tucumán (18951910)», Entrepasados. Revista de Historia, 35, Buenos Aires, comienzos de 2009, 67-87.

Breves Contribuciones del Instituto de Estudios Geográficos, Monografía I, Tucumán, Universidad Nacional de Tucumán, Facultad de Filosofía y Letras, 1988. 
Campi, Daniel: «Captación forzada de mano de obra y trabajo asalariado en Tucumán, 1856-1896», Anuario IEHS, VIII, Tandil, 1993, 47-71.

Campi, Azúcar y trabajo. Coacción y mercado laboral. Tucumán, 1856-1896, Tesis Doctoral (inédita), Madrid, Universidad Complutense, 2002.

Campi, «Bialet-Massé y los trabajadores tucumanos del azúcar», en Lagos, Marcelo; Fleitas, María Silvia y Bovi, María Teresa (comps.): A cien años del informe de Bialet Massé, Jujuy, Unidad de investigación en Historia Regional, Universidad Nacional de Jujuy, 2004, 175-190.

Campi, «Julio P. Ávila: Medios prácticos para mejorar la situación de las clases obreras, 1892», Comentario, Estudios del Trabajo, 30, Buenos Aires, juliodiciembre de 2005, 123-146.

Castel, Robert: La metamorfosis de la cuestión social, Buenos Aires, Paidós, 1997.

Curia de Villeco, María Elena y Bolognini, Víctor Hugo: Inmigración en Tucumán, Tucumán, Universidad Nacional de Tucumán, Facultad de Filosofía y Letras, Instituto de Historia y Pensamiento Argentino, 1992.

Di Stefano, Roberto: «Orígenes del movimiento asociativo: de las cofradías coloniales al auge mutualista», Luna, Elba y Cecconi, Elida (coords.): De las cofradías a las organizaciones de la sociedad civil. Historia de la iniciativa asociativa en Argentina, 1776-1990, Buenos Aires, Edilab, 2002, 23-97.

Falcón, Ricardo: «Notas sobre la cuestión social en Argentina», Cuadernos del CIESAL. Revista de Estudios multidisciplinarios sobre la cuestión social, Año 6, 6-7, Rosario, 1999-2000, 189-191.

Falcón, La Barcelona Argentina, Rosario, Laborde Editor, 2005.

Fernández, María Estela: «Salud y condiciones de vida. Iniciativas estatales y privadas, Tucumán fines del siglo XIX y comienzos del XX», Álvarez, Adriana; Molinari, Irene y Reynoso, Daniel (eds.): Historia de enfermedades, salud y medicina en la Argentina de los siglos XIX y XX, Mar del Plata, Universidad Nacional de Mar del Plata, 2004, 111-134.

García Soriano, Manuel: «El periodismo tucumano: 1817-1900. Ensayo de investigación sobre un aspecto de la cultura de Tucumán durante el siglo XIX», Cuadernos de Humanitas, 38, Tucumán, 1972, 1-113.

Girbal De Blacha, Noemí: «Estado, modernización azucarera y comportamiento empresario en la Argentina, 1876-1914», en Campi (comp.), Estudios sobre la historia de la industria azucarera argentina, 1991, 17-59.

González Leandri, Ricardo: «Notas acerca de la profesionalización médica en Buenos Aires durante la segunda mitad del siglo XIX»; Suriano (comp.): La cuestión social en Argentina, 1870-1943, 2004a, 217-243.

Guy, Donna: Politica azucarera argentina: Tucumán y la generación del 80, Tucumán, Fundación Banco Comercial del Norte, 1981.

Landaburu, Alejandra: «Organizaciones de la Sociedad Civil, trabajadores y empresarios azucareros. Tucumán, fines del siglo XIX y principios del XX», 
ponencia presentada en las X Jornadas Interescuelas/Departamentos de Historia, Universidad Nacional de Rosario, 2005.

Legislación laboral en Tucumán, Recopilación ordenada de Leyes, decretos y resoluciones sobre derecho del trabajo y seguridad social 1839-1969, La, T. I, Tucumán, Facultad de Derecho y Ciencias Sociales, Instituto del Trabajo Juan Bautista Alberdi, Universidad Nacional de Tucumán, 1969.

Lenis, María y Hernández, Pablo: «Prensa y poder en Tucumán a fines del siglo XIX y principios del XX. Panorama historiográfico y fuentes», ponencia presentada en las IX Jornadas Regionales de Investigación en Humanidades y Ciencias Sociales, Facultad de Humanidades y Ciencias Sociales de la Universidad Nacional de Jujuy, San Salvador de Jujuy, mayo de 2008.

Lobato, Mirta Zaida: «Repensar la cuestión social», Cuadernos del CIESAL. Revista de Estudios multidisciplinarios sobre la cuestión social, Año 6, 6-7, Rosario, 1999-2000, 193-197.

Lobato, «Entre la protección y la exclusión: Discurso maternal y protección de la mujer obrera, Argentina 1890-1934», Suriano (comp.): La cuestión social en Argentina, 1870-1943, 2004a, 245-275.

Mases, Enrique: «La cuestión indígena y los límites de la cuestión social», Cuadernos del CIESAL. Revista de Estudios multidisciplinarios sobre la cuestión social, Año 6, 6-7, Rosario, 1999-2000, 199-203.

Mases, Enrique; Frapiccini, A.; Rafort, G.; Lvovich, D.: El Mundo del trabajo: Neuquén 1884-1930, Neuquén, Grupo de Estudio de Historia Social (GEHISO), 1994, 88-90.

Prieto, Agustina: «Rosario, 1904: cuestión social, política y multitudes obreras», Estudios Sociales, Año X, 19, Santa Fe, 2000, 105-119.

Prieto, «'Usos de la 'cuestión obrera'. Rosario, 1901-1910», en Suriano (comp.): La cuestión social en Argentina, 1870-1943, 2004a, 63-87.

Rafart, Gabriel: «Algunos aportes para discutir la cuestión social», Cuadernos del CIESAL. Revista de Estudios multidisciplinarios sobre la cuestión social, Año 6, 6-7, Rosario, 1999-2000, 205-208.

Reynoso, Daniel: «Las políticas de salud: el caso de los hospitales en Tucumán a fines del siglo XIX», ponencia presentada en las X Jornadas Interescuelas/Departamentos de Historia, Rosario, 20 al 23 de septiembre de 2005.

Rojkind, Inés: «El malestar obrero. Visibilidad de la protesta social en Buenos Aires del novecientos», Travesía. Revista de historia económica y social, 1011, Tucumán, 2008/2009, 15-44.

Rosanvallón, Pierre: La nueva cuestión social. Repensar el Estado providencia, Buenos Aires, Manantial, 1995.

Sábato, Hilda: «Estado y sociedad civil», en Luna y Cecconi (coords.): De las cofradías a las organizaciones de la sociedad civil. Historia de la iniciativa asociativa en Argentina, 1776-1990, 2002, 99-167. 
Saltor, Irene: «Aspectos de la Modernidad. Tucumán, 1880-1890», Revista de la Junta de Estudios Históricos de Tucumán, Año VIII, 5, Tucumán, 1993, 3361.

Sánchez Román, José Antonio: La dulce crisis: estado, empresarios y industria azucarera en Tucumán, Argentina (1853-1914), Sevilla, Consejo Superior de Investigaciones Científicas, Escuela de Estudios Hispano-Americanos, Universidad de Sevilla, Diputación de Sevilla, 2005.

Suriano, Juan: «La cuestión social y el complejo proceso de construcción inicial de las políticas sociales en la Argentina moderna», Ciclos en la historia, la economía y la sociedad, Año XI, XI, 21, Buenos Aires, primer semestre de 2001, 123-147.

Suriano, «Introducción: una aproximación a la definición de la cuestión social en Argentina», en Suriano (comp.): La cuestión social en Argentina, 18701943, 2004a, 1-29.

Suriano, «Los historiadores y el proceso de construcción del estado social», Bertranou, Julián; Palacio, Juan Manuel; Serrano, Gerardo M.: En el país del no me acuerdo (Des) memoria institucional e historia de la política social en la Argentina, Buenos Aires, Prometeo, 2004b, 33-58, 43-44.

Suriano, «El largo camino hacia la ciudadanía social», Torrado, Susana (comp.): Población y bienestar en la Argentina del primero al segundo Centenario. Una historia social del siglo XX, Buenos Aires, Edhasa, 2007, I, 67-95.

Teitelbaum, Vanesa: Entre el control y la movilización. Trabajo, honor y solidaridades artesanales en la ciudad de México a mediados del siglo XIX, México, El Colegio de México, 2008.

Teitelbaum, «Hacia una política social. Higiene y trabajo en Tucumán del entre siglo», Anuario IEHS, 24, Tandil, 2009, 41-68.

Teitelbaum,Vanesa y Gutierrez, Florencia: «Las sociedades de artesanos y el poder público. Ciudad de México, segunda mitad del siglo XIX», Estudios de Historia Moderna y Contemporánea de México, 36, México, juliodiciembre de 2008, 127-158.

Teitelbaum y Gutiérrez, «El mutualismo artesanal: disciplinamiento y cooptación política (Ciudad de México, 1850-1886)», en Mallo, Silvia C. y Moreyra, Beatriz I. (coords.): Miradas sobre la historia social argentina en los comienzos del siglo XXI, Córdoba-La Plata, Centro de Estudios Históricos «Prof. Carlos S. A. Segreti»-Centro de Estudios de Historia Americana Colonial, 2008, 587-605.

Zimmermann, Eduardo: Los liberales reformistas. La cuestión social en la Argentina 1890-1916, Buenos Aires, Sudamericana-Universidad de San Andrés, 1995. 